\title{
AGC-1 Pre-Irradiation Data Report Status
}

\author{
David Swank
}

The INL is a

U.S. Department of Energy

National Laboratory

operated by

Battelle Energy Alliance

August 2011
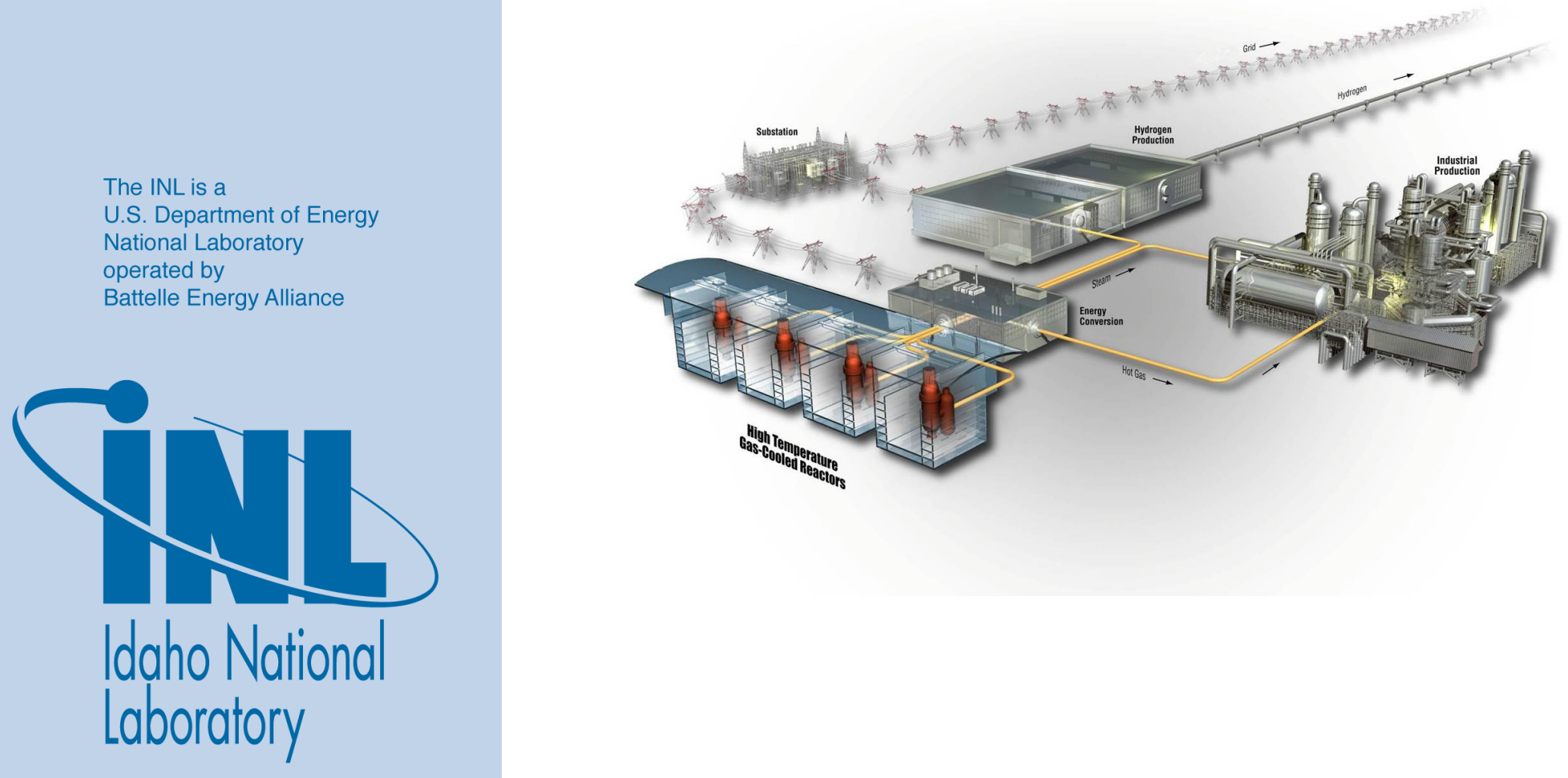


\section{DISCLAIMER}

This information was prepared as an account of work sponsored by an agency of the U.S. Government. Neither the U.S. Government nor any agency thereof, nor any of their employees, makes any warranty, expressed or implied, or assumes any legal liability or responsibility for the accuracy, completeness, or usefulness, of any information, apparatus, product, or process disclosed, or represents that its use would not infringe privately owned rights. References herein to any specific commercial product, process, or service by trade name, trade mark, manufacturer, or otherwise, does not necessarily constitute or imply its endorsement, recommendation, or favoring by the U.S. Government or any agency thereof. The views and opinions of authors expressed herein do not necessarily state or reflect those of the U.S. Government or any agency thereof. 


\title{
AGC-1 Pre-Irradiation Data Report Status
}

\author{
David Swank
}

August 2011

\section{Idaho National Laboratory \\ Next Generation Nuclear Plant Project \\ Idaho Falls, Idaho 83415}

http://www.inl.gov

Prepared for the

U.S. Department of Energy

Office of Nuclear Energy

Under DOE Idaho Operations Office

Contract DE-AC07-05ID14517 



\section{Next Generation Nuclear Plant Project}

\section{AGC-1 Pre-Irradiation Data Report Status}

INL/EXT-11-23163

August 2011

Author:

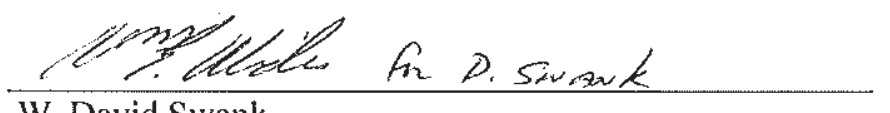

W. David Swank

NGNP Graphite

Approved by:

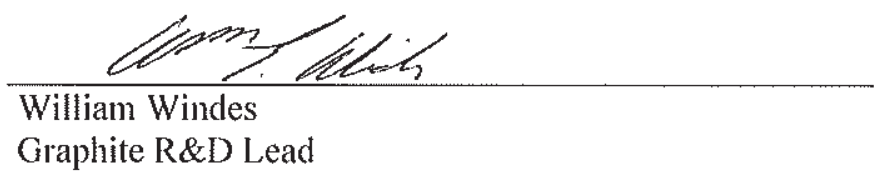

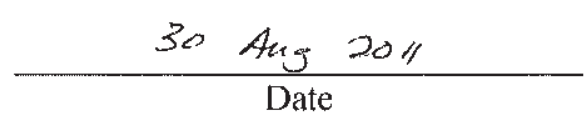

So Ang 2011

Date 



\begin{abstract}
The Next Generation Nuclear Plant (NGNP) Graphite Research and Development Program is currently measuring irradiated material property changes in several grades of nuclear graphite for predicting their behavior and operating performance within the core of new very high temperature reactor designs. The Advanced Graphite Creep experiment, consisting of six irradiation capsules, will generate this irradiated graphite performance data for NGNP reactor operating conditions. All samples in the experiment will be fully characterized before irradiation, irradiated in the Advanced Test Reactor, and then reexamined to determine the irradiation induced changes to key materials properties in the different graphite grades. The information generated during the Advanced Graphite Creep experiment will be used for Nuclear Regulatory Commission licensing of NGNP reactor designs, shared with international collaborators in the Generation IV Information Forum, and eventually used in American Society of Mechanical Engineers design code for graphite nuclear applications. This status report describes the process the NGNP Graphite Research and Development Program has developed to manage the AGC-1 preirradiation examination data.
\end{abstract}




\section{CONTENTS}

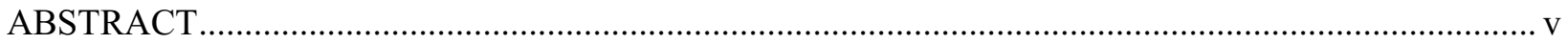

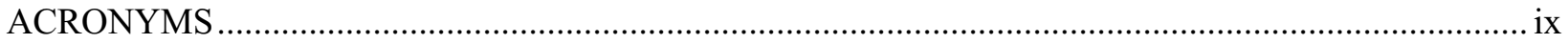

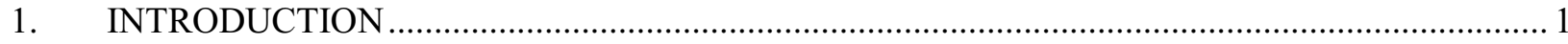

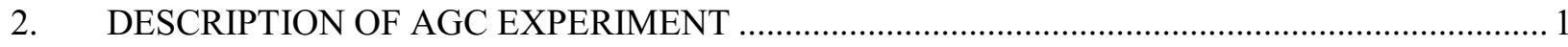

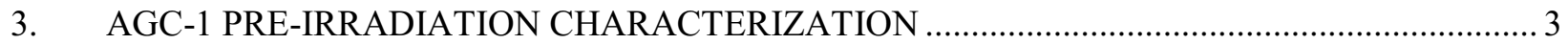

3.1 Preirradiation Examination of AGC-1 samples ...................................................................... 3

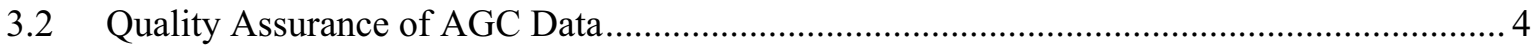

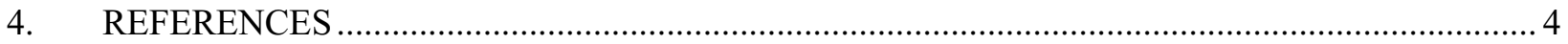

\section{FIGURES}

Figure 1. The INL Carbon Characterization Laboratory showing thermal testing equipment. ................... 2

Figure 2. ORNL's Low Activation Materials Development and Analysis (LAMDA) Laboratory.............2

Figure 3. The CCL glovebox used to visually inspect irradiated graphite samples, perform initial dimensional measurement, and repackage samples for storage in the irradiated graphite vault located in Lab C-19. 


\section{ACRONYMS}

AGC Advanced Graphite Creep

ASME American Society of Mechanical Engineers

ATR Advance Test Reactor

INL Idaho National Laboratory

IRC INL Research Center

CCL Carbon Characterization Laboratory

MFC Material and Fuels Complex

HFEF Hot Fuel Examination Facility

LAMDA Low Activation Materials Development and Analysis

NDMAS NGNP Data Management and Analysis System

NGNP Next Generation Nuclear Plant

PIE Post-Irradiation Examination

QA Quality Assurance

R\&D research and development 


\section{AGC-1 Pre-Irradiation Data Report Status}

\section{INTRODUCTION}

This status report describes the process the Next Generation Nuclear Plant (NGNP) Graphite Research and Development (R\&D) Program has developed to manage Advanced Graphite Creep (AGC) pre-irradiation examination data for the current AGC-1 samples and future AGC capsules. It also generally describes the AGC experiment, pre-irradiation testing, data quality assurance (QA) process, and process for entering the data package (the actual data values) into the NGNP Data Management and Analysis System (NDMAS) satellite data storage system.

\section{DESCRIPTION OF AGC EXPERIMENT}

The NGNP Graphite R\&D Program is currently measuring irradiated material properties for predicting the behavior and operating performance of new nuclear graphite grades available for use within the core of new very high temperature reactor designs. The AGC experiment, consisting of six irradiation capsules, will generate this irradiated graphite performance data for NGNP reactor operating conditions. The AGC experiment is designed to determine the changes to specific material properties such as thermal diffusivity, thermal expansion, elastic modulus, mechanical strength, irradiation-induced dimensional change rate, and irradiation creep for a wide variety of nuclear grade graphite types over a range of high temperature and moderate doses. A series of six capsules containing graphite test specimens will be used to expose graphite test samples to a dose range of 1 to $7 \mathrm{dpa}$ at three different temperatures: 600,900, and $1200^{\circ} \mathrm{C}$, as described in the Graphite Technology Development Plan (TDP). ${ }^{1}$ Since irradiation induced creep within graphite components is considered critical to determining the operational life of the graphite core, some of the samples will also be exposed to an applied load during exposure, to determine the creep rate for each graphite type under temperature and a neutron flux.

All six AGC capsules in the experiment will be irradiated in the Idaho National Laboratory (INL) Advanced Test Reactor (ATR). AGC-1 and AGC-2 capsules will be irradiated in the south flux trap while AGC-3through AGC-6 capsules will be irradiated in the east flux trap to accommodate NGNP irradiation priorities. After irradiation, all AGC capsules will be cooled in the ATR Canal, sized for shipment, and shipped to the Materials and Fuels Complex (MFC) where each capsule will be disassembled in the Hot Fuel Examination Facility (HFEF). During disassembly, the metallic capsule will be machined open and the individual samples removed from the interior graphite body containing the samples during irradiation. Samples removed from the capsule will be loaded in a shipping drum and shipped to the INL Research Center (IRC) for initial post-irradiation examination (PIE) and storage for any future testing at INL's recently completed Carbon Characterization Laboratory (CCL) or ORNL's Low Activation Materials Development and Analysis (LAMDA) Laboratory shown in Figures 1 and 2.

Both the CCL and LAMDA facilities are designed to characterize and test low activated irradiated materials such as high-purity graphite, carbon-carbon composites, and silicon-carbide ( $\mathrm{SiC}$ ) composite materials. The laboratories are fully capable of characterizing properties of both irradiated and nonirradiated materials, and will share the testing responsibilities for all AGC samples. The CCL will also process all specimens for initial visual inspections, dimensional measurements, and repackaging of samples (both irradiated and nonirradiated) for storage or shipping, as shown in Figure 3. 


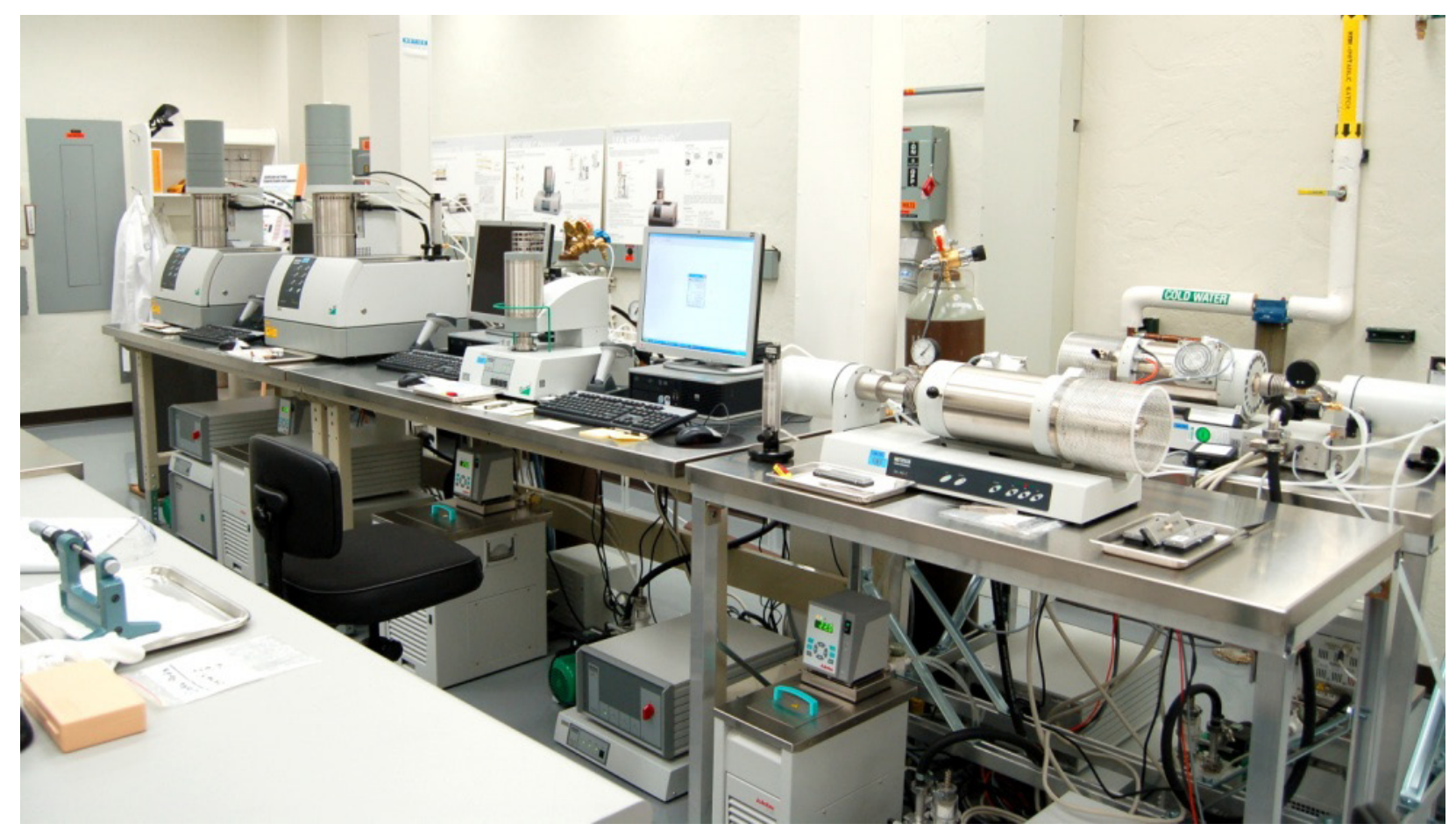

Figure 1. The INL Carbon Characterization Laboratory showing thermal testing equipment.

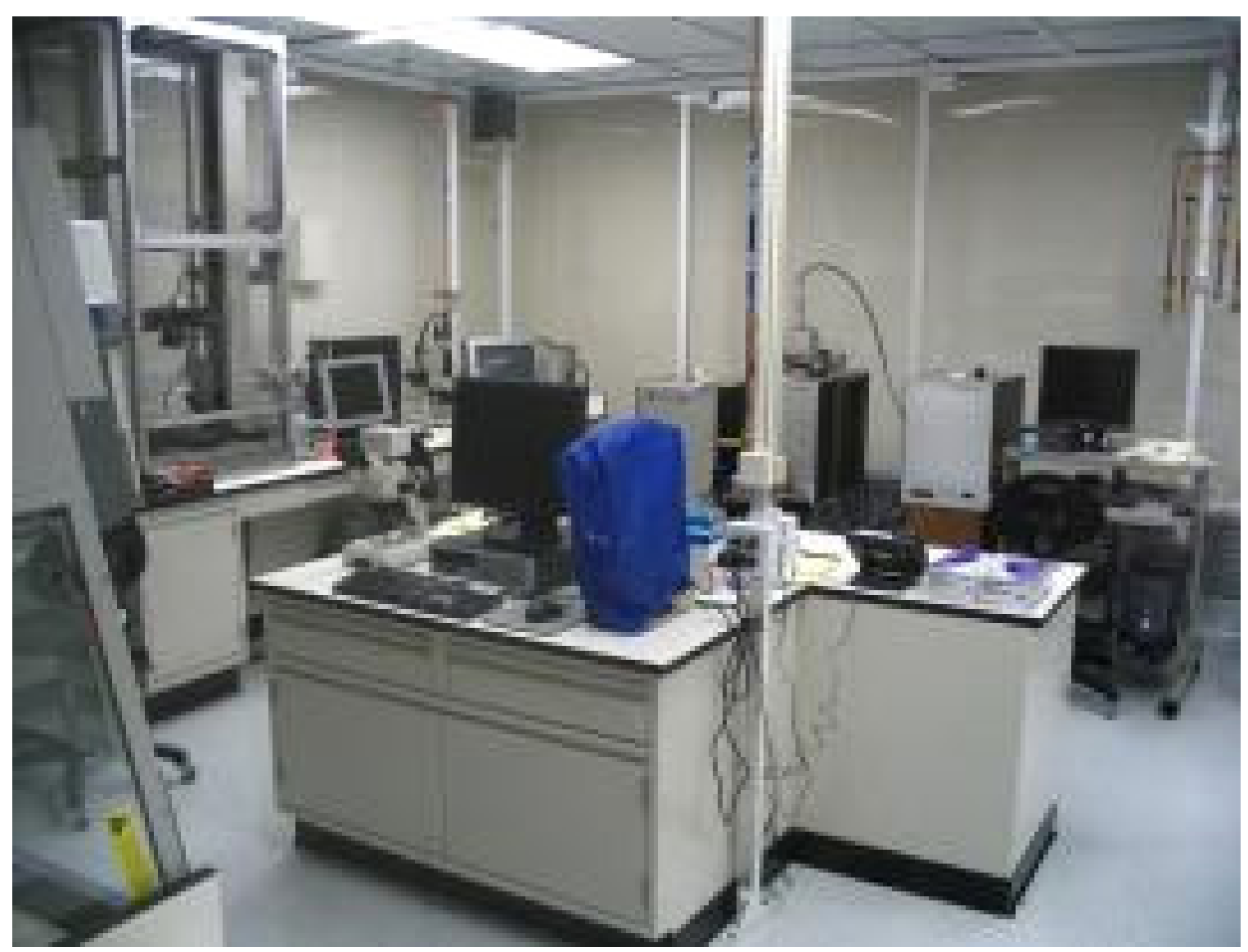

Figure 2. ORNL's Low Activation Materials Development and Analysis (LAMDA) Laboratory. 


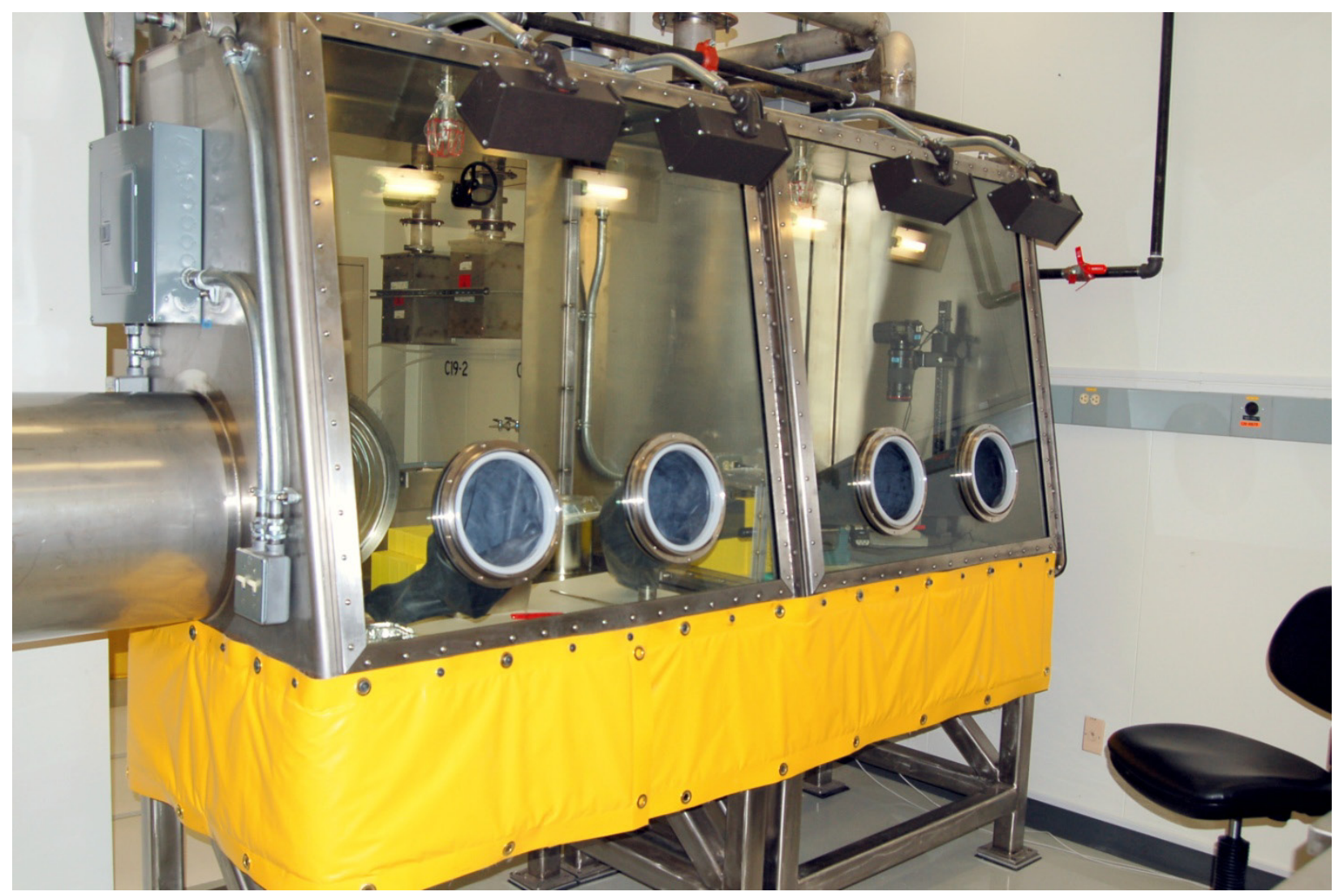

Figure 3. The CCL glovebox used to visually inspect irradiated graphite samples, perform initial dimensional measurement, and repackage samples for storage in the irradiated graphite vault located in Lab C-19.

\section{AGC-1 PRE-IRRADIATION CHARACTERIZATION}

A complete pre-irradiation testing and characterization program was conducted at the Oak Ridge National Laboratory (ORNL) on all graphite samples inserted into the AGC-1 capsule. ${ }^{2,3}$

After pre-irradiation testing was complete, the samples were loaded into the AGC-1 capsule, which was then inserted into the ATR. Capsule irradiation began September 5, 2009. After irradiation was completed on January 8, 2011, the capsule was cooled for 3 months and then shipped to MFC in April 2011 for disassembly and eventual post-irradiation testing.

\subsection{Preirradiation Examination of AGC-1 samples}

Pre-irradiation examination (characterization) data of AGC-1 graphite specimens will be officially documented in the Oak Ridge National Laboratory report (ORNL/TM-2010/285). ${ }^{4}$ Pre-irradiation examination consisted of precise dimensional measurements (before and after heating to $800^{\circ} \mathrm{C}$ in the dilatometer) and nondestructive characterization of the physical properties. The properties measured were: bulk density by mensuration, electrical resistivity, and elastic constants, including dynamic Young's modulus (fundamental frequency method), and sonic elastic constants, including Young's modulus, shear modulus, and Poisson's ratio; ambient temperature thermal conductivity; and Thermal Expansion $\left(\mathrm{RT}-800^{\circ} \mathrm{C}\right)$. Significant differences noted in the physical properties between the grades examined are attributed to factors such as density, structure (filler particle size and pore size), and the forming method. 
The data reported in ORNL/TM-2010/285 was previously delivered to INL as a data package in 2008. A number of transcription errors were identified and corrected during data evaluation and analysis while preparing that report. The future occurrence of such errors is unlikely, since both INL and ORNL testing and measurement equipment is being upgraded to allow electronic data recording. This action was taken after consultation with NGNP QA to ensure the quality of the data was sufficient for its intended use in reactor safety design, Nuclear Regulatory Commission licensing activities, and American Society of Mechanical Engineers (ASME) code development.

\subsection{Quality Assurance of AGC Data}

NGNP QA reviewed and approved all experimental plans, primarily using ASTM International standards for the pre-irradiation testing and measurement of the AGC samples. ${ }^{2,3}$ The computer-based data acquisition software mentioned previously was also reviewed and approved by the NGNP QA group as meeting all NQA-1 requirements. After testing and measurements were completed, the data was analyzed and formally recorded in a data report. ${ }^{4}$ To assure data quality, each report was peer reviewed by an external DOE laboratory (e.g., ORNL/TM-2010/285 was reviewed by INL graphite researchers) accompanied by review documentation. Each data report will eventually be entered into INL's Electronic Data Management System as official records for the pre-irradiation material property results of each AGC capsule.

After completing the official record of the pre-irradiation characterization results, the data contained with the data reports will be electronically stored in the NDMAS satellite data storage system. A data evaluation report (FRM-1073) will be generated for each AGC Data Package (the data electronically stored in NDMAS) ${ }^{5}$ to ensure the data is properly identified in the satellite system.

AGC-1 pre-irradiation material property data for dimensional measurements, resonance-modulus, thermal diffusivity, sonic velocity, electrical resistivity, and thermal expansion data for 277 piggyback and 192 creep specimens contained in the AGC-1 irradiation capsule was independently verified as having been collected according to NGNP Graphite R\&D data collection plans, and was entered into the NDMAS satellite storage system. A copy of the AGC-1 Pre-Irradiation Examination Data Package is attached. This data will now be available for reactor safety design, NRC licensing activities, and ASME code development. It will also be used to meet international commitments to the Generation IV Information Forum.

\section{REFERENCES}

1 W. Windes, T. Burchell, and R. Bratton, “Graphite Technology Development Plan,” PLN-2497, Rev. 1, October 2010.

2 Tim Burchell, Graphite Irradiation Creep Capsule AGC-1 Experimental Plan, ORNL/TM-2005/505, May 2005.

3 T. Burchell, A Revised AGC-1 Creep Capsule Layout, ORNL/TM-2009/009, January 2009.

4 T. Burchell, J. Strizak, and M. Williams, AGC-1 Specimen Pre-irradiation Data Report, ORNL/TM-2010/285, August 2011.

5 W. Windes, AGC-1 Pre-Irradiation Examination Data Package, 30 August 2011. 
APPENDIX A

Data Evaluation Report 
Section 1. Data Source Description

Contact Information (name, address, phone num, email)

Will Windes 526-6985

Larry Hull 526-1922

Data ID \#

AGC1 Pre-Irradiation Examination $\quad 30$ Aug 2011

Data Package

Data Description (type and scope)

AGC1 pre-irradiation characterization data to be stored in NDMAS. Type A Data. Data provided by ORNL per ORNL/TM-2010/285. This data is to be used for reactor design, NRC licensing, GIF commitments, and ASME code development. The data is considered to be critical to the NGNP VHTR TDO program.

Identify technical and subject matter disciplines required to evaluate data

Technical Evaluator : R\&D researcher NGNP VHTR TDO

QA Evaluator: Quality Engineer NGNP VHTR TDO

Data Entry : Data Specialist for NDMAS

\begin{tabular}{|c|c|c|}
\hline Section 2. Evaluation Team & \multicolumn{2}{|c|}{ Add additional members as an attachment if necessary } \\
\hline Technical Lead Name & Email & Phone number \\
\hline Will Windes & William.Windes@inl.gov & $526-6985$ \\
\hline \multicolumn{3}{|c|}{$\begin{array}{l}\text { Description of experience, skills that pertain to evaluating this data set } \\
\text { Graphite Lead for NGNP VHTR TDO }\end{array}$} \\
\hline Technical Investigator Name & Email & Phone number \\
\hline David Swank & W.Swank@inl.gov & $526-1698$ \\
\hline Description of experience & skills that pertain to evaluating this data set & Description of experience \\
\hline \multicolumn{3}{|c|}{ David Swank R\&D researcher NGNP VHTR TDO. } \\
\hline Project manager Name & Email & Phone number \\
\hline Travis Mitchell & Travis.Mitchell@inl.gov & $526-3864$ \\
\hline \multicolumn{3}{|c|}{$\begin{array}{l}\text { Description of experience, skills that pertain to evaluating this data set } \\
\text { Program Manager NGNP VHTR TDO. }\end{array}$} \\
\hline Quality Engineer Name & Email & Phone number \\
\hline David R. Jensen & David.Jensen@inl.gov & $526-5428$ \\
\hline \multicolumn{3}{|c|}{$\begin{array}{l}\text { Description of experience, skills that pertain to evaluating this data set } \\
\text { Quality Engineer NGNP VHTR TDO }\end{array}$} \\
\hline Data Specialist Name & Email & Phone number \\
\hline Larry Hull & Laurence.Hull@inl.gov & $526-1922$ \\
\hline
\end{tabular}


FRM-1073

$06 / 13 / 2011$

\section{Data Evaluation Report}

Rev 1

Page 2 of 3

Section 3. Qualifying Methods

Quality Assurance Program: Criteria

ORNL is a NQA-1 2000 qualified laboratory as found in the INL Qualified Suppliers List.

Peer Review: Criteria

Data from tests meet the requirements of the test plan as identified in ORNL/TM-2010/285.

Anomalies in the data were identified and resolved by personnel from INL and ORNL.

Data Corroboration: Criteria

NA

Confirmatory Testing: Criteria

NA

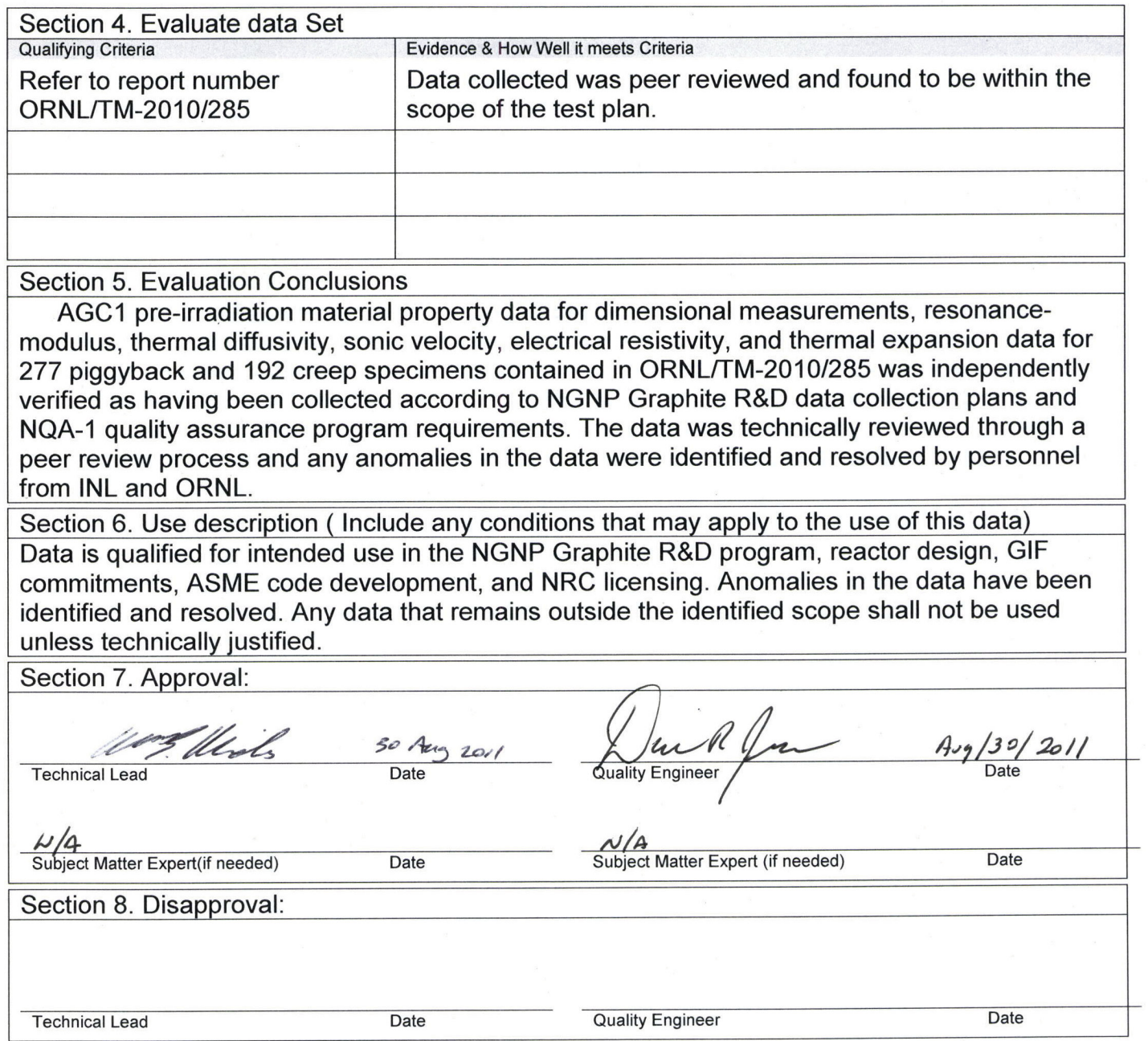


FRM-1073

$06 / 13 / 2011$

Rev 1

Data Evaluation Report

Section 9. Concurrence:
Page 3 of 3

Project Manager

Date 